\title{
Innovar o no innovar, ¿he ahí el dilema?
}

Creatividad es pensar cosas nuevas. Innovación es hacer cosas nuevas.

Theodore Levitt

La única forma de tener buenas ideas es tener muchas ideas.

Linus Pauling

\section{¿Qué nos depara el 2018?}

Escribo estas líneas al final del primer mes del año, momento en que hemos abandonado muchos de nuestros propósitos de año nuevo. Como cada ciclo anual, hacemos un colosal esfuerzo por aprovechar las lecciones aprendidas y usarlas para planear las actividades y logros del presente año. Aunque la sabiduría popular recomiende ser más optimista que pesimista, es inevitable ante la coyuntura actual local, nacional y mundial, adoptar una actitud de cierta resignación ante el torbellino de situaciones desagradables y complicadas que nos abruman, a veces hasta el punto de la toxicidad. Sin entrar en detalle sobre los retos existentes, que pueden empeorar si no se toman decisiones difíciles y complejas con el concierto de autoridades, ciudadanía, academia e industria; baste decir que es nuestra obligación como ciudadanos y seres humanos conscientes, participar activamente en todos los niveles de influencia individual y grupal para que nuestro contexto mejore.

Es ahí donde las publicaciones de divulgación científica tenemos una gran responsabilidad: exhibir de manera clara y sensata conocimientos, argumentos, narrativas y diversos tipos de información de diversas disciplinas, para el consumo y reflexión de la comunidad universitaria y la sociedad en general. Hay una amplia oferta de publicaciones impresas y digitales sobre todo tipo de temas, por lo que deseamos aportar nuestro grano de arena universitario sobre la necesidad de desarrollar el pensamiento crítico, ampliar nuestros horizontes a veces tan estrechamente disciplinarios y actuar en la medida de lo posible para contribuir a la mejoría de nuestras condiciones de vida. Para ello se requiere creatividad e innovación, entre otras cosas, conceptos que necesitan diseminación para tener un impacto en nuestra conducta y actividades. 
Revista Digital Universitaria

Vol. 19, Núm. 1, enero-febrero 2018

\section{¿Es la palabra 'innovación' un lugar común?, ¿necesitamos revivirla?}

Uno de los términos más comúnmente utilizados para describir la necesidad de cambio, es 'innovación'. Desafortunadamente por repetición y exceso de uso, el concepto ha sido tomado como bandera por personas, grupos e instituciones, y se ha convertido en un 'lugar común', es decir "Expresión trivial, o ya muy empleada en caso análogo" (RAE, 2018). ¿Cuántas veces hemos visto u oído en la red, televisión, radio y propaganda escrita las siguientes frases: "somos una empresa innovadora", "nuestro equipo se dedica a la innovación", "usamos métodos innovadores", "nuestro lema es la innovación"? Para colmo, en el curriculum vitae de cualquier persona que busca trabajo suele decir: "soy una persona innovadora, reflexiva, resiliente, asertiva, líder, colaboradora... etcétera, etcétera".

El resultado es que, de la misma manera que términos como paradigma, liderazgo, rendición de cuentas y empoderamiento, entre otros, la palabra se usa excesiva e inapropiadamente en situaciones que no corresponden al intento original. Como consecuencia, tendemos a no hacerle mucho caso ni a reflexionar sobre su potencial utilidad en nuestro trabajo diario. Deberíamos hacer un alto en el camino y apropiarnos del concepto y estrategias de la innovación en nuestras actividades.

Estamos tan frecuentemente agobiados por el exceso de datos e información que recibimos a través de nuestros dispositivos electrónicos y los medios de comunicación, que nos cuesta trabajo hacer pausas para reflexionar sobre si hacemos las cosas de la mejor forma posible. Se dice que la única constante de la vida moderna es el cambio, sin embargo, nos comportamos de manera bastante rutinaria. Pensar sobre la innovación puede ayudarnos a salir de la inercia de la vida diaria, e identificar mejores y diferentes maneras de interactuar con nuestro entorno.

Las definiciones de innovación son múltiples, desde descripciones tan sencillas como "algo nuevo", "cambiar algo", "introducir novedades", hasta aproximaciones más sofisticadas con teorías que la abordan como un concepto complejo y multidimensional. Una de las definiciones que más me atraen, sobre todo porque va ligada al desarrollo de habilidades de liderazgo transformacional, es la propuesta por Banny Banerjee de Stanford: "Innovación es la habilidad de superar enfoques normativos con un margen significativo, producir nuevos valores, resultados, paradigmas y transformaciones" (Banerjee, 2017). Las conductas innovadoras requieren creatividad y receptividad al cambio, aunque la creatividad por sí sola no garantiza la innovación (por ejemplo, un criminal puede ser muy 'creativo' al realizar sus crímenes, pero en el concepto que deseamos promover de innovación, no lo llamaríamos 'criminal innovador'). Con frecuencia se confunde la innovación con el 'emprendimiento' (entrepreneurship en inglés), concepto que ha adquirido gran visibilidad debido a la intensa competencia entre empresas y organizaciones comerciales para lograr más ventas entre sus clientes. Si bien el emprendimiento puede requerir acciones innovadoras, creemos que el concepto de innovación es más amplio y no se constriñe a las actividades comerciales o de negocios, en las que el principal objetivo es la ganancia de mercado.

Por otra parte, en países como el nuestro, en los que el número de patentes aceptado como indicador de innovación es relativamente bajo, vale la pena también conceptualizar a la

Universidad Nacional Autónoma de México, Coordinación de Desarrollo Educativo e Innovación Curricular (CODEIC) Este es un artículo de acceso abierto bajo la licencia de Creative Commons 4.0 
Revista Digital Universitaria

Vol. 19, Núm. 1, enero-febrero 2018

innovación desde el punto de vista sociológico. De acuerdo a Rogers, innovación es "una idea, práctica u objeto que es percibido como nuevo por un individuo u otra unidad de adopción" (Rogers, 2003). En esta perspectiva, una innovación no es algo que no existía previamente, sino que es percibida como novedosa por la persona o grupo a la que es expuesta (por ejemplo, para un individuo que nunca ha usado Twitter, esta red social es una innovación, aunque hayan pasado varios años desde su creación original). Un aspecto relevante de la visión sociológica de las innovaciones es que amplía la visión a elementos más allá de los dispositivos tecnológicos o informáticos tangibles, ya que una innovación puede ser una idea o una manera diferente de hacer las cosas. jCada vez hay más maneras innovadoras de conceptualizar a la innovación!

\section{¿Podemos (debemos) innovar en educación?}

Por diversas razones, el foco de la innovación en las últimas décadas se ha dirigido principalmente a las áreas de la tecnología, la informática, el comercio, entre otras, con un énfasis en la inmediatez, gratificación inmediata y ganancia financiera. A la par, una de las actividades humanas más importantes (algunos diríamos que jla más importante!), la educación, ha sido extraordinariamente resistente a incorporar el concepto de innovación en su cotidianeidad. Los seres humanos tendemos a ser muy conservadores en varias de nuestras actividades, y la manera en que enseñamos y aprendemos suele ser una de ellas. Aunque incorporemos instrumentos y metodologías novedosas en nuestro quehacer disciplinario (seamos médicos, ingenieros, arquitectos, escritores, abogados...), con frecuencia enseñamos, evaluamos y aprendemos de formas similares a las que fuimos educados y evaluados (perpetuando esas conductas cuando adoptamos los roles de docente y evaluador del aprendizaje de estudiantes).

En las últimas décadas ha surgido un movimiento creciente a nivel internacional, que busca alinear nuestros métodos de enseñanza y aprendizaje con los avances del conocimiento. Ello implica actualizarse, desarrollar e incorporar innovaciones en el ámbito educativo de los diferentes niveles, básico, medio superior, superior y educación continua a lo largo de la vida. A la innovación educativa, como al concepto moderno de innovación en general, es menester pensarla no solo como un cambio o algo novedoso, además debe ser un medio para mejorar el aprendizaje y producir cambios positivos. En este sentido, la innovación se define como: "la selección, organización y utilización creativas de recursos humanos y materiales, de maneras nuevas y propias que den como resultado un nivel más alto con respecto a metas y objetivos previamente marcados" (en Moreno,1995). El potencial de la innovación educativa, disruptiva o no, en el contexto universitario moderno, es gigantesco. Los esquemas que hemos utilizado en el último siglo han generado muchos resultados positivos, pero existen todavía muchos retos que no se han resuelto con los métodos tradicionales, y que requieren obligadamente esfuerzos colaborativos transdisciplinarios, intra e interinstitucionales.

En el presente número de la revista, se reporta la experiencia de una iniciativa de Rectores de universidades públicas y privadas (véase artículo "Presentan la red 360 de innovación educativa"), que pretende explorar nuevos esquemas de trabajo colaborativo y generación de ideas. Estamos firmemente convencidos que la innovación educativa debe crecer, diseminarse y ayudar a transformar el conflictivo mundo moderno que habitamos. Si la única constante en la vida moderna es el cambio, debemos propiciar que la educación de los habitantes de

Universidad Nacional Autónoma de México, Coordinación de Desarrollo Educativo e Innovación Curricular (CODEIC Este es un artículo de acceso abierto bajo la licencia de Creative Commons 4.0 
Revista Digital Universitaria

Vol. 19, Núm. 1, enero-febrero 2018

nuestro país y del mundo sea de la mejor calidad posible, con los mejores maestros y en las mejores instituciones.

Editor en jefe

Melchor Sánchez Mendiola

Facultad de Medicina, UNAM

\section{Referencias}

- Banerjee, B. (2016). "Why innovate?". En Banerjee, B., Ceri, S. Eds. Creating Innovation Leaders. A Global Perspective. Springer International Publishing: Switzerland. pp. 3-24. Recuperado de: http://www. springer.com/br/book/9783319205199.

* Barraza Macías, A. (2005). Una conceptualización comprehensiva de la innovación educativa. Innovación Educativa, 5(28):19-31. Recuperado de: http://www.redalyc.org/html/1794/179421470003/.

* Hernández, Mirtha (2017). Presentan la Red 360 de innovación educativa. En Gaceta Digital UNAM. Número 4,916. Lunes 30 de octubre de 2017. Recuperado de: http://www.gaceta.unam. $\underline{\mathrm{mx} / 20171030 / \text { presentan-la-red-360-de-innovacion-educatival. }}$

* Moreno Bayardo, María Guadalupe (1995). Investigación e innovación educativa. Revista La Tarea. Núm. 7.

Real Academia Española (2018). Lugar común. http://dle.rae.es/?id=NgMEY5T, Consultado en febrero de 2018.

Rogers, E. M. (2003). Diffusion of Innovations. $5^{\circ}$ edición. Simon and Schuster: Nueva York.

\section{Cómo citar este artículo}

* Sánchez Mendiola, Melchor (2017). Innovar o no innovar, che ahí el dilema? Revista Digital Universitaria (RDU), vol. 19, núm. 1, enero-febrero. DOl: http://doi.org/10.22201/codeic.16076079e.2018. $\underline{\mathrm{v} 19 \mathrm{n} 1 . \mathrm{a} 0}$ 